Sharif University of Technology
Scientia Iranica
SCIENTIA
I RAN ICA
http://scientiairanica.sharif.edu

\title{
Rock pillar stress analysis to obtain effective dimensioning and guarantee the mining void stability
}

\author{
M. Ranjbarnia ${ }^{a, *}$, P. Oreste ${ }^{\mathrm{b}}$, and A. Fahimifar ${ }^{\mathrm{c}}$ \\ a. Department of Geotechnical Engineering, Faculty of Civil Engineering, University of Tabriz, 29 Bahman Boulevard, Tabriz, Iran. \\ b. Department of Environment, Land and Infrastructure Engineering, Politecnico di Torino, Corso Duca Degli Abruzzi 24, Turin \\ 10129, Italy. \\ c. Department of Civil and Environmental Engineering, Amirkabir University of Technology, Hafez Ave, Tehran, Iran.
}

Received 3 November 2015; received in revised form 7 October 2016; accepted 12 November 2016

\section{KEYWORDS}

Rock pillar;

Mining engineering;

Void stability;

Numerical modeling;

Stress analysis.

\begin{abstract}
In the room and pillar mining method, dimensioning of the pillars is of fundamental importance. Nowadays, the area of influence method is typically used for dimensioning of the pillars; however, over-dimensioning or critical stability conditions can happen in this method. A parametric analysis with three-dimensional numerical modelling was carried out to study the stress conditions of rock pillars in details. This helped to identify a critical point, where the minimum local safety factor was reached, at the corners of the pillar close to the roof of the mining room. Through the estimation of the major principal stress at the critical point, it was possible to evaluate the minimum local safety factor through the geometric and geomechanical parameters of the problem. The dimensioning of the pillars through the local safety factor at the critical point helps to avoid over-dimensioning and static problems, which can occur when simplified calculation methods are used. The use of the proposed figures can allow a fast pre-dimensioning of the pillars, leaving the more detailed numerical modelling only for the found geometric configuration.

(C) 2018 Sharif University of Technology. All rights reserved.
\end{abstract}

\section{Introduction}

The collapse of rock from the roof of excavations or from the lateral surfaces of pillars is the cause of $15 \%$ of the accidents that involve workers inside mining voids created with the room and pillar method [1]. The collapse of a pillar can also cause the subsidence phenomenon on the surface and further potential static problems on the structure [2].

The dimensioning of rock pillars in underground

\footnotetext{
*. Corresponding author.

E-mail addresses: m.ranjbarnia@tabrizu.ac.ir (M. Ranjbarnia); pierpaolo.oreste@polito.it (P. Oreste); fahim@aut.ac.ir (A. Fahimifar)
}

mines, excavated by void methods, is one of the most interesting problems of rock engineering. Many studies were developed over the last century in order to get into more details of this subject and be able to conduct a dimensioning that, on the one hand, leads to the stability of underground voids and, on the other hand, makes the maximum recovery of the mineralized rock possible.

The area of influence method has generally been used in the last decades to estimate the mean axial stress in the pillar. Many researchers have developed formulations in order to determine the pillar strength and, therefore, the safety factor of the pillar.

The simplicity of the method has led to rough approximations in the evaluation of the pillars stability. In fact, studying room and pillar mines in the East of the United States, Esterhuizen et al. [1] observed the 
collapse of pillars even if the safety factors were between 1 and 4 . For this reason, the dimensioning of pillars in rock mines, using the area of influence method, should require relatively high safety factors (usually more than $3)$.

Mortazavi et al. [3] found from a numerical calculation that pillars behaved in different ways during the post-rupture phase regarding the width/height ratio: narrow pillars (low width/height ratio) showed brittle elastic-plastic behaviour, with a remarkable decay of the mean axial stress of the pillar on reaching rupture; squat pillars (relatively high width/height ratio, above the unit) showed ideal elastic-plastic behaviour, with a constant mean axial stress value in the post-rupture phase as the mean axial deformations progressed; very squat pillars (very high width/height ratio, above 1.5) showed hardening elastic-plastic behaviour, with appreciable increases in the mean axial stress as the mean axial deformation progressed in the post-rupture phase.

On the basis of these considerations, the necessity of requesting higher safety factors for narrow pillars, which can collapse suddenly once rupture is reached, emerges while it is possible to assume lower safety factors for squat and very squat pillars, which can however show elevated strength, even in the presence of evident signs of rupture of the pillar.

Kaiser and Tang [4] showed that when the elastic modulus of the rock on the roof of a void was much lower than that of the rock of the pillars, the rupture phase of a pillar was of a brittle elastic-plastic type, as the great energy accumulated by the rock on the roof and on the floor was suddenly discharged onto the pillar until it ruptured. Jaeger and Cook [5] sustained that the rupture of the pillar could be violent in these cases, and rock blocks could even be thrown from the side walls. Again, in these cases, given the great risks for the underground workers connected to the rupture of the pillar, it is necessary to foresee high safety factors.

Nowadays, the area of influence method cannot be used to dimension a rock pillar. Different methods, like three-dimensional numerical and analytical modelling [6-9], can be adopted to determine the stress strain state inside the pillar and, therefore, the local safety factors in the rock mass.

The work presented in this article was carried out with the aim of conducting a detailed analysis of the stress state induced inside pillars and developing more sophisticated dimensioning techniques in order to drastically reduce the risk of the fall of rock blocks from the side surfaces of rock pillars and avoid the risk of the collapse of a pillar, with the consequent collapse of the rooms and the pillars nearby.

The stability of pillars without important internal natural discontinuities or layers of poor rock with a tendency to extrude is dealt with in the following sections. The presence of such anomalies can in fact lead to collapse phenomenon concerning pillars with specific characteristics [1]; this requires detailed analyses of the characteristics of the discontinuities (roughness, alterations, fillings, persistence, aperture, direction, and dip) or the layer of poor rock inside the pillar.

\section{The area of influence method}

A simplified picture of the stresses induced in a pillar can be obtained from a simple analysis of the equilibrium of forces. Figure 1 shows a horizontal section of an underground mining panel with pillars arranged in a regular pattern. The widths of the room and pillars are $I$ and $w_{p}$, respectively.

Because of equilibrium of forces:

$$
\sigma_{p}^{\prime} \cdot A_{p}=\sigma_{v 0}^{\prime} \cdot A_{c}
$$

where $\sigma_{p}^{\prime}$ is mean vertical stress in the pillar; $A_{p}$ stands for transversal section area of the pillar $\left(A_{p}=\right.$ $\left.w_{p x} . w_{p y}\right) ; A_{c}$ represents competence area of the pillar:

$$
A_{c}=\left[\left(\frac{l_{x}}{2}+w_{p x}+\frac{l_{x}}{2}\right) \cdot\left(\frac{l_{y}}{2}+w_{p y}+\frac{l_{y}}{2}\right)\right] .
$$

$\sigma_{v 0}^{\prime}$ is lithostatic vertical stress at the depth of the

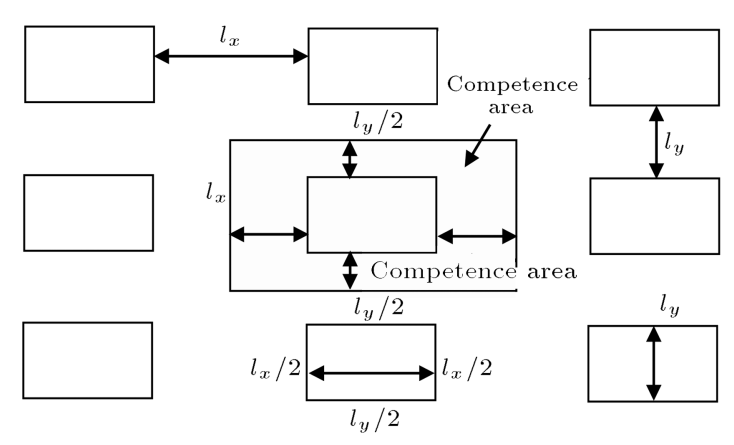

(a)

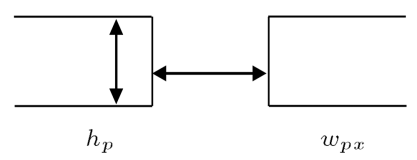

(b)

Figure 1. Simplified geometric scheme of an underground mining panel in the room and pillar method: (a) Horizontal section, and (b) vertical section. 
chamber roof; $w_{p x}$ and $w_{p y}$ are widths of the pillars in the two horizontal directions, $x$ and $y ; l_{x}$ and $l_{y}$ are widths of the chamber in the two horizontal directions, $x$ and $y$. From Eq. (1) the following is obtained:

$$
\sigma_{p}^{\prime}=\sigma_{v 0}^{\prime} \cdot \frac{A_{c}}{A_{p}}=\sigma_{v 0}^{\prime} \cdot \frac{\left(w_{p x}+l_{x}\right) \cdot\left(w_{p y}+l_{y}\right)}{\left(w_{p x} \cdot w_{p y}\right)} .
$$

The original natural vertical stress, $\sigma_{v 0}^{\prime}$, is not generally known, except for when certain determinations are conducted on site. In order to have a preliminary estimation, it is possible to refer to the simple expression, $\sigma_{v 0}^{\prime}=\gamma^{\prime} . z$, where $z$ is the mean depth of the room roof. The estimation of the natural horizontal stress, $\sigma_{h 0}^{\prime}$, is much more problematic, but it is important above all when separation slabs are foreseen between the different mining levels. Even in the case of mining on only one level, the natural horizontal stress influences the stress-strain behaviour of the pillar, in particular close to the end zones at the top and bottom [10].

Eq. (2) shows that the mean axial stress induced in a pillar $\left(\sigma_{p}^{\prime}\right)$ can be calculated by starting directly from the dimensions of the room and the pillar and from the vertical stress found at the height of the room roof in natural conditions (before creating the mining voids).

The extraction ratio, $r$, which is the ratio of volume of the extracted rock to the total volume of rock in the mining panel, is given by the following expression:

$$
r=\frac{A_{c}-A_{p}}{A_{c}}=1-\frac{A_{p}}{A_{c}} .
$$

From Eqs. (2) and (3), it is possible to write $\sigma_{p}^{\prime}=\frac{\sigma_{v 0}^{\prime}}{1-r}$, by which it is possible to see how the mean stress in the pillar grows hyperbolically to infinity with $r$ as it comes closer to 1 . The mean stress in the pillar increases considerably for small increases in $r$ when its value is above 0.75 .

For square section pillars $\left(w_{p}=w_{p x}=w_{p y}\right)$ and for rooms of the same width $\left(l=l_{x}=l_{y}\right)$, Eq. (2) can be simplified in the following manner:

$$
\sigma_{p}^{\prime}=\sigma_{v 0}^{\prime} \cdot \frac{\left(w_{p}+l\right)^{2}}{w_{p}^{2}} .
$$

When the area of influence method is used to calculate the axial stress in the pillar, it is advisable to consider the following drawbacks:

- The mean axial stress in the pillar is a purely convenient quantity that is used to represent the loading state of a pillar in the vertical direction; in reality, the axial stresses can vary to a great extent inside the transversal section with respect to the position of the transversal section of the pillar that is considered;
- The stresses in the two directions perpendicular to the axial one and the three shear stresses that exist in the three-dimensional space inside the pillar are not considered; only the mean value of one of the six stress components that exist inside the pillar is considered;

- As the mean value of the vertical stress is only considered, the effects produced by the horizontal lithostatic stresses, as well as those of any possible difference between stiffness (elastic modulus) of the rock on the roof and on the foot and the stiffness of the rock of which the pillar is made, are neglected;

- The effect of the position of the pillar inside the mining panel is ignored.

\section{Considerations for the strength of pillars}

The evaluation of the strength of a pillar, which should be compared with mean axial stress, $\sigma_{p}^{\prime}$, to obtain the safety factor of the pillar, is the most important aspect of the problem, when the simplified approach of the area of influence method is adopted.

All the formulations that are available to obtain the strength of rock pillars have been obtained from an analysis of the behaviour of real structures, imposing a safety factor value equal to 1 (conditions for which the mean axial stress is equal to the strength of the pillars) for all the cases in which the pillar has shown extreme stability conditions at the limit of collapse or with collapse already underway [1,11] (Figure 2).

For this reason, most formulations on the strength of pillars consider not only the volume of the pillar, which can in fact have a certain direct influence on the strength value of the rock mass, but also the shape (which is usually described by the slenderness $h_{p} / w_{p}$ or by its inverse), which reflects the distribution of the stresses inside the pillar. In this way, one attempts to compensate for the great simplification that is made when evaluating the induced stress state, taking into consideration one of the most important aspects (the shape) that can condition the development of the stresses inside the pillars.

The effect of the volume on the strength can be understood immediately in terms of distribution of the natural discontinuities of the rock mass. As the volume increases, so does the probability that there may be more discontinuities in the rock.

Hoek and Brown [12] clearly showed that a reduction in strength of the intact rock occurred as the diameter of a laboratory sample increased. The data were made dimensionless by dividing the individual strength values by the strength of a 50-mmdiameter specimen, which was the typical dimension of a laboratory sample. The same authors suggested that the uniaxial compressive strength, $\sigma_{c d}$, of a rock 


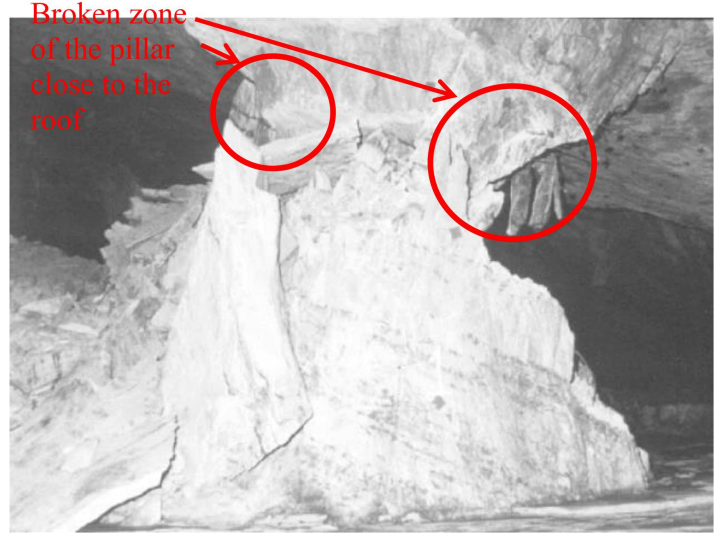

(a)

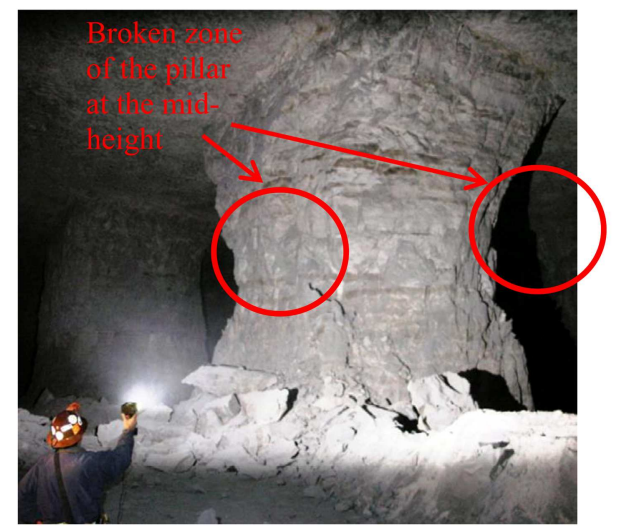

(b)

Figure 2. Collapse and incipient collapse conditions of pillars for which a safety factor of 1 is hypothesised: (a) The case of a quartzite pillar (from Martin and Maybee [11]), and (b) the case of a granite pillar (from Esterhuizen et al. [1]).

specimen, with a diameter, $d$, in $\mathrm{mm}$, depended on the uniaxial compressive strength, $\sigma_{c 50}$, of a $50-\mathrm{mm}-$ diameter specimen by the following relation:

$$
\sigma_{c d}^{\prime}=\sigma_{c 50}^{\prime} \cdot\left(\frac{50}{d}\right)^{0.18}
$$

where:

$\sigma_{c d}^{\prime} \quad$ The uniaxial compressive strength of the intact rock, measured on a specimen of diameter $d(\mathrm{~mm})$;

$\sigma_{c 50}^{\prime} \quad$ The uniaxial compressive strength of the intact rock, measured on a 50-mm-diameter specimen.

Experimental tests on specimen in the laboratory show that the increase in the dimension of the specimen leads to a reduction in its strength. The important definition of "critical dimension," defined as the dimension of a specimen for which a further increase in the width does not cause a significant increase in strength, belongs to this context. Different authors have attempted to determine this magnitude with regards to the type of material the pillar is made of.

The definition of the critical magnitude is important because the strength values relative to the critical magnitude can be applied directly to the whole pillar.

The effect of the slenderness of the pillar basically arises from the stress confinement that develops inside the pillar, as a result of the impossibility of deforming laterally, which is imposed by the rock on the roof and floor of the pillar in correspondence with its upper and lower extremes; a slender pillar is less influenced by these constraints in the central portion of the pillar, while a squat pillar is more influenced with a positive contribution to its stability.

Lunder and Pakalnis [13] estimated that the mean confinement in a pillar $\left(\sigma_{3 m}^{\prime}\right)$ can be expressed with regards to its slenderness, $h_{p} / w_{p}$ :

$$
\frac{\sigma_{3 m}^{\prime}}{\sigma_{p}^{\prime}}=0.46 \cdot\left[\log \left(\frac{1}{\left(h_{p} / w_{p}\right)}+0.75\right)\right]^{1.4 \cdot \frac{h_{p}}{w_{p}}} .
$$

Moreover, Maybee [14] showed that the lateral confining stresses were negligible inside slender pillars $\left(w_{p} / h_{p}<0,5\right)$, and that the influence of the natural lateral thrust coefficient $k$ (ratio between the horizontal and vertical stresses in natural conditions) on the lateral confinement stresses inside a pillar only occurred in squat pillars $\left(w_{p} / h_{p}>1\right)$.

However, the influence of the coefficient $k$ is only felt for $w_{p} / h_{p}>1.25$.

For all the reasons mentioned above, the strength of a pillar is generally evaluated with regards to the aforementioned two parameters (volume and shape):

$$
\sigma_{s t r}^{\prime}=\sigma_{s t r, 0}^{\prime} \cdot V_{p}^{a} \cdot \frac{1}{\left(h_{p} / w_{p}\right)^{b}}
$$

where:

$\sigma_{s t r, 0}^{\prime} \quad$ The reference uniaxial compressive strength (referring to a unitary volume);

$V_{p}$ and $h_{p}$ The volume and height of the pillar;

$w_{p} \quad$ The minimum dimension of the pillar.

As an alternative, simpler expressions can be used of this type:

$$
\sigma_{s t r}^{\prime}=\sigma_{s t r, 0}^{\prime} \cdot h_{p}^{\alpha} \cdot w_{p}^{\beta} .
$$

The values of the exponents $a$ and $b$, or $\alpha$ and $\beta$, which different authors have found in their studies, are reported in Salamon and Munro [15]. The typical values of these parameters are:

$$
\begin{aligned}
& \alpha=0.5 / 1, \quad \beta=0.46 / 0.50, \\
& a=0.07 / 0.17, \quad a=0.4 / 0.8 .
\end{aligned}
$$


Hardy and Agapito [16] compared the volume and slenderness of a pillar with the volume and slenderness of a laboratory specimen, in bituminous schists, in order to obtain the strength of the pillar $\sigma_{\text {str }}^{\prime}$ as the percentage reduction in the uniaxial compressive strength of the intact rock $\sigma_{c i}^{\prime}$ :

$$
\frac{\sigma_{s t r}^{\prime}}{\sigma_{c i}^{\prime}}=\left(\frac{V_{p}}{V_{s}}\right)^{-0.118} \cdot\left(\frac{h_{s} / w_{s}}{h_{p / w_{p}}}\right)^{0.833}
$$

where:

$V_{p}$ and $V_{s}$ The volumes of the pillar and of the rock specimen for the uniaxial compressive test in the laboratory, respectively;

$h_{s}$ and $w_{s}$ The height and the diameter of the laboratory specimen, respectively, for which $\sigma_{c i}^{\prime}$ is evaluated;

$\sigma_{c i}^{\prime} \quad$ The uniaxial compressive strength of intact rock measured in the laboratory.

Many other formulae have been developed over the years and each of them refer to the specific situations for which they are obtained. Extrapolation to other situations (in relation to the type of rock, the dimensions and shape of the pillars, and the lithostatic stress state) could even lead to relevant errors.

Martin and Maybee [11], for example, evaluated the $\sigma_{s t r}^{\prime} / \sigma_{c i}^{\prime}$ ratio for a $5 \mathrm{~m}$ high pillar on the basis of different empirical correlations, varying the $w_{p} / h_{p}$ ratio (the inverse of slenderness). Pillar strength values very different from each other were found: $\sigma_{\text {str }}^{\prime}$ varied in the $0.2-0.4 . \sigma_{c i}^{\prime}$ interval for $w_{p} / h_{p}=0.5$ (slender pillars) and varied in the $0.4-0 . \sigma_{c i}^{\prime}$ interval for $w_{p} / h_{p}=3.0$ (very squat pillars).

Gonzalez-Nicieza et al. [17] obtained the strength of a pillar of $10 \mathrm{~m} \times 10 \mathrm{~m}$ at the bottom, varying the height of the pillar according to different empirical correlations taken from literature, considering a uniaxial compressive strength of the intact rock equal to $100 \mathrm{MPa}$. Again, in this case, there was a great dispersion of the results obtained with the different empirical formulations. For a height of $5 \mathrm{~m}$, the strength of the pillar varied as much as 20-80 $\mathrm{MPa}$, while for a height of $15 \mathrm{~m}$, it varied in the 8-48 MPa interval.

It is obvious that a designer, when faced with this large variability of strength values of pillars, would cautiously choose the minimum value from those proposed by various authors (the value proposed by Potvin et al. [18] for $w_{p} / h_{p}$ below 0.75 or that proposed by Krauland and Soder [19] for $w_{p} / h_{p}$ equal to or higher than 0.75; the value proposed by CMRI-Central Mining Research Institute in Dhanbad in India [20] for $h_{p}$ below $7 \mathrm{~m}$ or that proposed by Hardy and
Agapito [16] for $h_{p}$ equal to or higher than $7 \mathrm{~m}$ ). This uncertainty can, in the best of cases, lead to an overdimensioning (sometimes also excessive) of the pillars. Instead, if the minimum value of the strength estimated by the different empirical correlations is not assumed, it is possible to run the risk of foreseeing pillars that are not able to bear the loads produced by the rock on the roof, which would inevitably lead to their collapse.

This important variability of the strength values of pillars leads to the conclusion that the simplistic approach of the areas of influence can no longer be accepted, and that it is necessary to obtain a complete and reliable evaluation of the stress state inside pillars and to define exact safety factors inside the rock that make up the individual pillars.

The observation of pillars in critical stability conditions allows us to establish the portions of the pillars that tend to break off first, when collapse does not occur suddenly. Gonzalez-Nicieza et al. [17] identified different degrees of criticality of a pillar from the stress point of view: damage to one or more cornerstones and their tendency to become round; damage to one or more lateral faces (such a degree of criticality is considered as the evolution of the previous one, when the stress state induced in the pillar is such that it leads to the rupture and breaking off of the rock between the already damaged cornerstones); rupture that occurs in the pillar, which leads to the further detachment of rock from all the lateral walls until the typical hourglass shape is reached (Figure 3 ).

\section{Analyses of the stress state and the local safety factors in pillars with a three-dimensional numerical method}

An extended parametric analysis using the FLAC $3 \mathrm{D}$ [21] numerical method was performed in order to analyse the behaviour of single rock pillars [22-24], considering the most frequent geometries for square pillars and deep excavations.

Elastic behaviour of the rock mass was considered; however, the value of the elastic modulus did not have any effect on the results. The pressure applied to the upper surface of the model was equal to $1 \mathrm{MPa}$; the stress state induced in the rock pillar was linear dependent on this pressure, which was influenced by the depth of the excavations.

The adopted numerical elements were cubic with the dimension of $0.25 \mathrm{~m}$.

After having attributed the mechanical properties of the rock and the boundary conditions on the borders, the elements in the chamber zones around the pillar were annulled simulating the mining excavation of the chambers.

The analysed pillar geometries are reported in Table 1 [23]. A $w_{p} / h_{p}$ ratio interval of $0.2-1.2$ and 


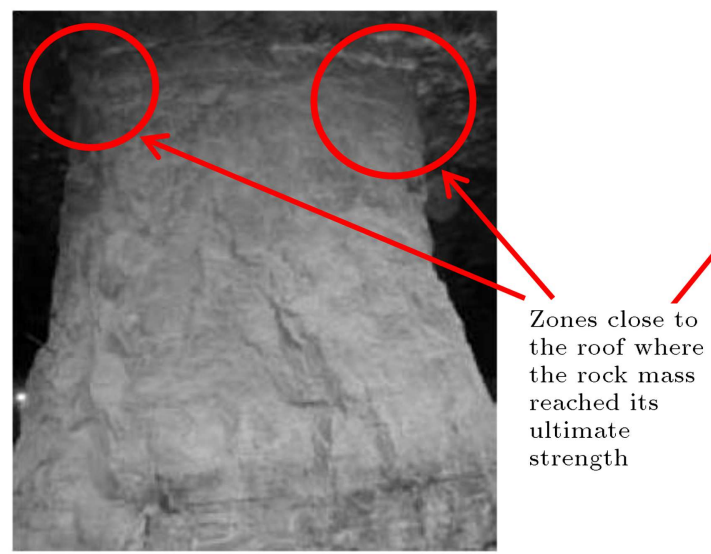

(a)

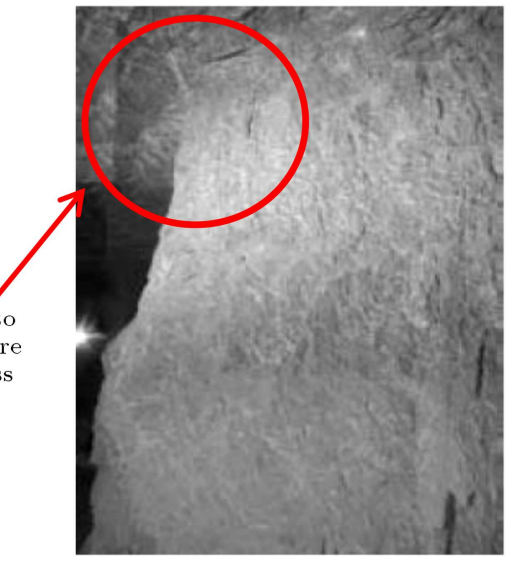

(b)

Figure 3. Damage to pillars in critical stress conditions: (a) Damage to several cornerstones in the pillar area close to the point of contact with the roof, and (b) damage to one or more lateral faces of a pillar in the upper part of the pillar (from Gonzalez-Nicieza et al. [17]).

Table 1. Dimensions of the pillars and the model, and values of $w_{p} / h_{p}$ and $l / w_{p}$ ratios in the performed three-dimensional numerical analyses.

\begin{tabular}{ccc}
\hline $\begin{array}{c}\text { Width of the pillar } \\
\left(\boldsymbol{w}_{\boldsymbol{p}}\right)(\mathbf{m})\end{array}$ & $\begin{array}{c}\boldsymbol{l} / \boldsymbol{w}_{\boldsymbol{p}} \\
\text { ratio }\end{array}$ & $\begin{array}{c}\boldsymbol{w}_{\boldsymbol{p}} / \boldsymbol{h}_{\boldsymbol{p}} \\
\text { ratio }\end{array}$ \\
\hline 3 & 1.66 & 0.50 \\
3 & 1.66 & 0.30 \\
3 & 1.66 & 0.21 \\
3 & 2.33 & 0.50 \\
3 & 2.33 & 0.30 \\
3 & 2.33 & 0.21 \\
3 & 3.00 & 0.50 \\
3 & 3.00 & 0.30 \\
3 & 3.00 & 0.21 \\
5 & 1.60 & 0.83 \\
5 & 2.40 & 0.83 \\
5 & 3.20 & 0.83 \\
7 & 1.57 & 1.17 \\
7 & 1.57 & 0.70 \\
7 & 2.43 & 1.17 \\
7 & 2.43 & 0.70 \\
7 & 3.29 & 1.17 \\
7 & 3.29 & 0.70 \\
\hline
\end{tabular}

$l / w_{p}$ ratio interval of $1.6-3.3$ were considered in the parametric analyses. They are typical interval values for mining excavations in medium-high strength rocks.

All the stresses, in particular the major $\left(\sigma_{1}^{\prime}\right)$ and minor $\left(\sigma_{3}^{\prime}\right)$ principal stresses, were monitored for each element (Figure 3 ). These stresses are of fundamental importance to determine the exact local strength of the rock mass inside the pillar and the exact local safety factor concerning rupture of the rock mass.
The images of major and minor stresses contours induced in the rock pillar are shown in Figures 4 and 5 . As well, the values of the major and minor principal stresses along different alignments inside the pillar for the cases of $w_{p} / h_{p}=0.70$ and $l / w_{p}=2.43$ are shown in Figures 6 and 7 as examples.

It is possible to note how the major principal stresses at mid-height of the pillar reach a value of about 1.03 times the mean vertical stress $\sigma_{p}^{\prime}$ in the portion close to the pillar axis, a value of $0.98 . \sigma_{p}^{\prime}$ at half of one of its sides, and a value of about $0.94 . \sigma_{p}^{\prime}$ in the corners. At an intermediate height of $3 / 4 . h_{p}$ (that is, at a distance of $1 / 4 . h_{p}$ from the top of the pillar), the major principal stress in the zone close to the pillar axis no longer shows the maximum value and has a value of about $0.98 . \sigma_{p}^{\prime}$; this stress slightly decreases at midheight of the side $\left(0.97 . \sigma_{p}^{\prime}\right)$ and rises to $0.98 \sigma_{p}^{\prime}$ in the corner. Finally, the major principal stress close to the pillar axis is very low (about $0.80 . \sigma_{p}^{\prime}$ ) at the summit of the pillar (at a distance of about $1 / 8 . h_{p}$ from the room roof), while it considerably grows when moving towards the peripheral zones of the pillar: $1.12 . \sigma_{p}^{\prime}$ at half the side and 1.43. $\sigma_{p}^{\prime}$ in the corner.

From an analysis of the stress state, with particular reference to the major principal stresses $\left(\sigma_{1}^{\prime}\right)$ and minor principal stresses $\left(\sigma_{3}^{\prime}\right)$, it emerges that a point of great interest in the evaluation of the stability conditions of the rock is the corner in the upper portion of the pillar, close to the point of contact with the room roof (at a distance of $1 / 8 . h_{p}$ from the point of contact with the roof). The major principal stress in fact reaches its maximum value in this critical point and the minor principal stress is reduced to zero (absence of lateral confinement). This circumstance has been verified in all of the performed numerical models. From an analysis of the obtained results, it has been possible to identify the influence of the $w_{p} / h_{p}$ ratio on the major 


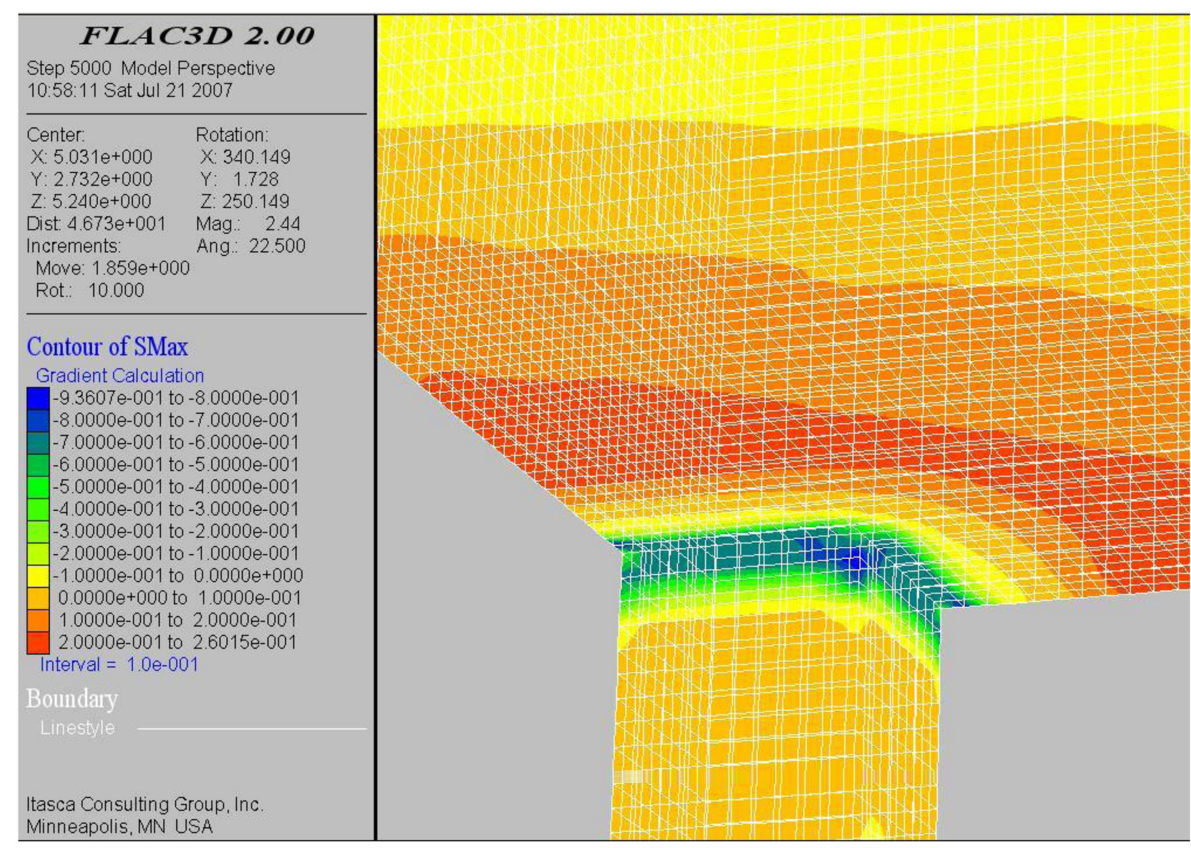

Figure 4. Example of the stress state (major principal stress) obtained by the 3D numerical calculation using the FLAC code, in one of the models developed in the parametric analysis.

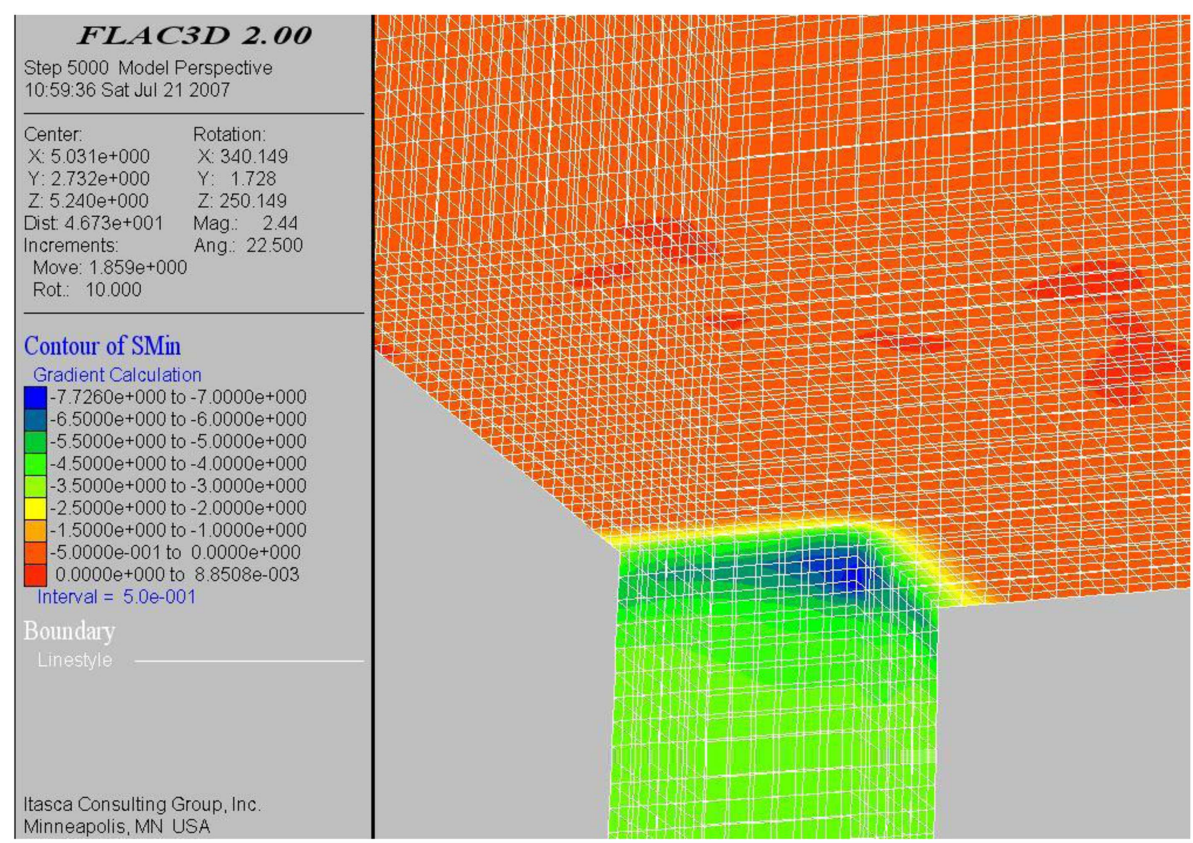

Figure 5. Example of the stress state (minor principal stress) obtained by the 3D numerical calculation using the FLAC code, in one of the models developed in the parametric analysis.

principal stress that develops at the critical point. The relation obtained through a linear regression of the results is as follows:

$$
\left(\frac{\sigma_{1}^{\prime}}{\sigma_{p}^{\prime}}\right)_{c p} \cong 1.27+0.28 \cdot \frac{w_{p}}{h_{p}},
$$

where $\left(\frac{\sigma_{1}^{\prime}}{\sigma_{p}^{\prime}}\right)_{c p}$ is the ratio of the major principal stress to the mean stress in the pillar at the previously described critical point.

Therefore, an increase in the major principal stress in the critical point can be observed for an increase in the $w_{p} / h_{p}$ ratio.

For the Hoek and Brown strength criterion of the rock mass $[12,25,26]$, the strength stress $\left(\sigma_{1, s t r}^{\prime}\right)$ is dependent on the minimum principal stress $\left(\sigma_{3}^{\prime}\right)$, the 


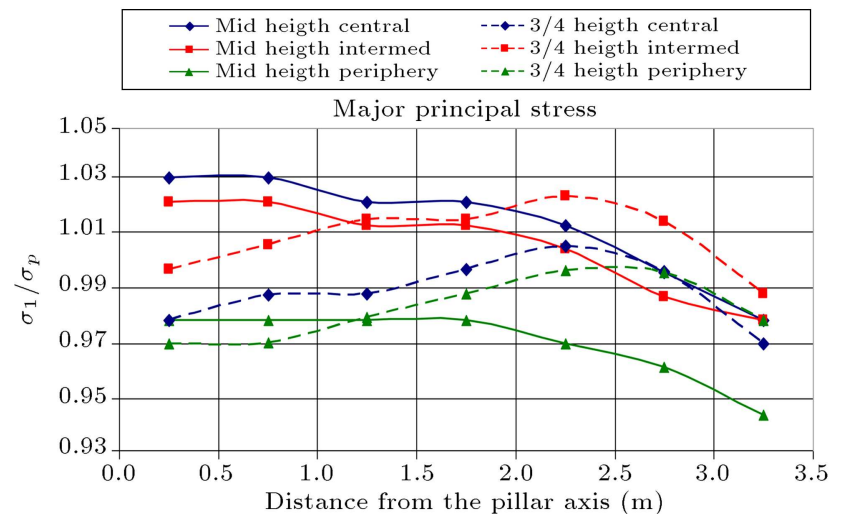

Figure 6. Trend of the major principal stress in different alignments inside a square pillar $\left(w_{p} / h_{p}=0.70\right.$ and $\left.l / w_{p}=2.43\right)$. Key: Mid height: $1 / 2 h_{p}$ from the pillar foot; $3 / 4$ height: $3 / 4 . h_{p}$ from the pillar foot; central: horizontal alignment passing through the pillar axis; periphery: horizontal alignment passing over the pillar side; and intermediate: horizontal alignment between the central and periphery.

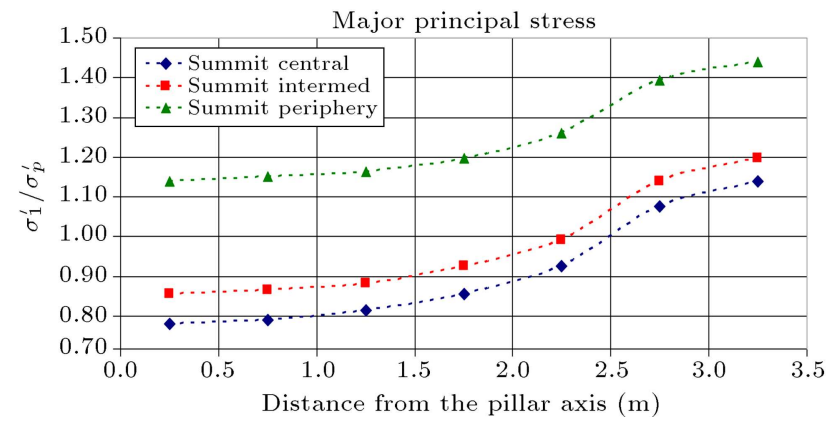

Figure 7. Trend of the major principal stress in different alignments inside a square pillar $\left(w_{p} / h_{p}=0.70\right.$ and $\left.l / w_{p}=2.43\right)$. Key: Summit: close to the pillar top; central: horizontal alignment passing through the pillar axis; periphery: horizontal alignment passing over the pillar side; and intermediate: horizontal alignment between the central and periphery.

uniaxial compressive strength of the intact rock $\left(\sigma_{c i}^{\prime}\right)$, and three strength parameters [26,27], which are functions of GSI and the disturbance factor $D[25,28,29]$ :

$$
\sigma_{1, s t r}^{\prime}=\sigma_{3}^{\prime}+\sigma_{c i}^{\prime} \cdot\left(m_{b} \cdot \frac{\sigma_{3}^{\prime}}{\sigma_{c i}^{\prime}}+s\right)^{a}
$$

where $\sigma_{1, s t r}^{\prime}$ is the strength of the rock mass in the presence of the lateral confinement stress $\sigma_{3}^{\prime} ; m_{b}$ and $s$ are the strength parameters from the Hoek and Brown strength criterion;

$$
\begin{aligned}
& m_{b}=m_{i} \cdot e^{\frac{G S I-100}{28-14 \cdot D}}, \\
& s=e^{\frac{G S I-100}{9-3 \cdot D}} \\
& a=\frac{1}{2}+\frac{1}{6} \cdot\left(e^{-\frac{G S I}{15}}-e^{-\frac{20}{3}}\right) .
\end{aligned}
$$

$m_{i}$ is a coefficient that is obtained from triaxial load tests on rock samples in the laboratory, and it is possible to estimate it, as a first approximation, with regards to the type of rock [27]; $D$ is a parameter that varies between 0 and 1 , which depends on the intensity of the disturbance caused by the adopted mining technique on the rock mass [26] (if no disturbance is produced on the rock mass by the excavation techniques [30], a $D$ parameter equal to 0 can be considered); and $\sigma_{c i}^{\prime}$ is the uniaxial compressive strength of the intact rock measured in the laboratory on cylindrical rock samples.

In the absence of lateral confinement $\left(\sigma_{3}^{\prime}=0\right)$, Eq. (10) is reduced to:

$$
\sigma_{1, s t r}^{\prime}=s^{a} \cdot \sigma_{c i}^{\prime} \text {, }
$$

and $\sigma_{1, s t r}^{\prime}$ can be considered as the uniaxial compressive strength of the rock mass $\left(\sigma_{c r m}^{\prime}\right)$.

For intact rock in the laboratory, or in situ in the absence of natural discontinuities in the rock mass (when the GSI is close to 100), Eq. (10) is reduced to:

$$
\sigma_{1, s t r}^{\prime}=\sigma_{3}^{\prime}+\sigma_{c i}^{\prime} \cdot\left(m_{i} \cdot \frac{\sigma_{3}^{\prime}}{\sigma_{c i}^{\prime}}\right)^{\frac{1}{2}} .
$$

From Eq. (10), it is possible to see how the strength of the rock mass in a point depends on the frequency of the discontinuities and their undulation, roughness, and alternation (GSI); the type of rock $\left(m_{i}\right)$; the uniaxial compressive strength of the intact rock $\left(\sigma_{c i}^{\prime}\right)$; and the lateral confinement stress (the minor principal stress $\left.\sigma_{3}^{\prime}\right)$. The same rock mass shows different values of strength in different internal points depending on the lateral confinement stress that is present in these points.

Cai et al. [28] stated that the GSI index could be applied for rock masses with a GSI $<75$. The discontinuities are not very frequent in rock masses with a GSI > 75, and the behaviour of the rock mass is conditioned by the presence of single discontinuities that represent zones of weakness inside the intact rock. In these cases, it is necessary to evaluate the stress and strain state that develops along the discontinuities in order to be able to obtain indications of the degree of stability of the pillar. When the GSI is close to 100 (the maximum value that can be reached by this index), the rock mass is affected by rare and not very persistent discontinuities, and can therefore be assimilated to the intact rock that is studied in the laboratory.

Singh and Rao [31] noted, from laboratory tests on artificial composite materials (with discontinuities), how the uniaxial compressive strength and deformation modulus of a rock mass were connected by the following relation:

$$
\frac{\sigma_{c r m}^{\prime}}{\sigma_{c i}^{\prime}}=\left(\frac{E_{r m}}{E_{i}}\right)^{0.63}
$$


where:

$\sigma_{c r m}^{\prime}$

The uniaxial compressive strength of the rock mass;

$E_{r m}$ and $E_{i}$ The elastic moduli of the rock mass and the intact rock measured in the laboratory.

Being able to measure the elastic modulus of the rock mass in situ and that of the intact rock in the laboratory, it is possible to obtain the rock mass strength, $\sigma_{\text {crm }}^{\prime}$, from Eq. (13) instead of using the estimation obtained from Eq. (11).

The Laubscher formulation [32] is also interesting. In this formulation, the mean strength of the in situ rock mass can be determined starting from Bieniawski's well-known classification:

$$
\sigma_{c r m}^{\prime}=\sigma_{c i}^{\prime} \cdot\left(\frac{\mathrm{RMR}-\mathrm{IRS}}{85}\right) \cdot k_{s} \cdot k_{d} \cdot k_{g} \cdot k_{e}
$$

where RMR stands for the Rock Mass Rating, the geomechanical quality index of the rock mass according to Bieniawski; IRS is Bieniawski's classification points referring to the mechanical property of the intact rock; $k_{s}$ is the coefficient that takes into account the scale effect between the behaviour of the pillar and that of the laboratory specimen (which the author suggested to be equal to 0.8$) ; k_{d}, k_{g}$, and $k_{e}$ are reductive coefficients to consider the effects produced by the degradation due to atmospheric agents (0.9-1), the orientation of the joints (0.8-1), and the dynamic action of the explosives (0.9-1).

The local safety factor of a point inside a rock pillar can be obtained by the following equation:

$$
F_{s}=\frac{\sigma_{1, s t r}^{\prime}}{\sigma_{1}^{\prime}}
$$

where:

$\sigma_{1, s t r}^{\prime} \quad$ The strength stress in the rock mass;

$\sigma_{1}^{\prime} \quad$ Maximum principal stress in a point inside the pillar.

In this way, it is possible to evaluate the trend of the local safety factors inside the rock mass and, in particular, to identify the zones with a minimum safety factor. The pillar can therefore be dimensioned by stating that the minimum local safety factor in the pillar is above a certain threshold value.

Safety factors were evaluated in each numerical element into which the pillar was divided for the 18 geometrical case analysed by means of the threedimension numerical analysis and illustrated above, considering 27 different types of rock, obtained by permuting the following parameters:

- GSI index: 50, 75, and 100;
- $m_{i}$ index for the intact rock: 12,20 , and 28;

- uniaxial compressive strength of the intact rock, $\sigma_{c i}^{\prime}$ : 20, 60, and $100 \mathrm{MPa}$.

These values describe the typical field of variation of rock masses with medium-high strength, in which it is normal practice to proceed with the room and pillar method.

Moreover, three different values of $\sigma_{v 0}^{\prime}$ (vertical lithostatic stresses at the depth of the mining room roof) were considered: 1,5 , and $9 \mathrm{MPa}$ (values that roughly correspond to the following depths: 40, 200 and $360 \mathrm{~m}$ ).

In this way, the local safety factors inside the pillar were evaluated, considering 27 (types of rock) $\times$ 3 (vertical lithostatic stresses) $\times 18$ (geometrical case analysed in the three-dimension models) for a total of 1458 types of pillar.

The minimum local safety factor inside the pillars was determined for each of these cases. After having discarded the minimum safety factors with values below unity (unacceptable and therefore unrealistic condition) and safety factors with too high values (above 5 ), it was found that in all cases, the minimum safety factor was located at the corners, close to the point of contact with the rock on the roof of the mining room (the critical point described in the previous section, found at a distance of about $1 / 8$ the height of the pillar from the point of contact with the roof). The lateral confinement stress is null at this point. Moreover, the major principal stress (which coincides with $\sigma_{z}$ ) can be estimated with regards to the $w_{p} / h_{p}$ ratio and the vertical lithostatic stress at the depth of the roof of the mining room (Eq. (16)). Therefore, on the basis of Eqs. (4), (9), and (10) and the Hoek and Brown strength criterion, it is possible to write the minimum local safety factor inside the pillar with the following simple relation:

$$
\begin{aligned}
F_{s, \min }= & \frac{\sigma_{c i}^{\prime}}{\sigma_{v 0}^{\prime}} \cdot \frac{w_{p}^{2}}{\left(w_{p}+l\right)^{2}} \\
& \cdot \frac{e^{\left(\frac{G S I-100}{9-3 \cdot D}\right) \cdot\left[\frac{1}{2}+\frac{1}{6} \cdot\left(e^{-\frac{G S I}{15}}-e^{-\frac{20}{3}}\right)\right]}}{1.27+0.28 \cdot \frac{w_{p}}{h_{p}}} .
\end{aligned}
$$

Once the depth of the pillar (and therefore the lithostatic stress state $\left.\sigma_{v 0}^{\prime}\right)$, the mechanical characteristics of the intact rock $\left(\sigma_{c i}^{\prime}\right)$, the rock mass (GSI and the disturbance intensity parameter $D)$, and the dimensions of the mining room (width $I$ and height $h_{p}$ ) are known, stating that the minimum local safety factor is above a certain threshold value, $F_{s}^{*}$, it is possible to calculate the minimum dimension of $w_{p}$ for which $F_{s, \min } \geq F_{s}^{*}$. 


\section{Application example of the proposed formulation}

The proposed formulation of Eq. (16) was used in order to evaluate the local minimum safety factor of the rock inside a pillar for different mechanical and geometrical configurations that could be met. A specific weight of $25 \mathrm{kN} / \mathrm{m}^{3}$ was adopted in the calculations. In Figures 8-16, the local minimum safety factor is obtained for typical values of GSI, $\sigma_{c i}^{\prime}, w_{p}$ and

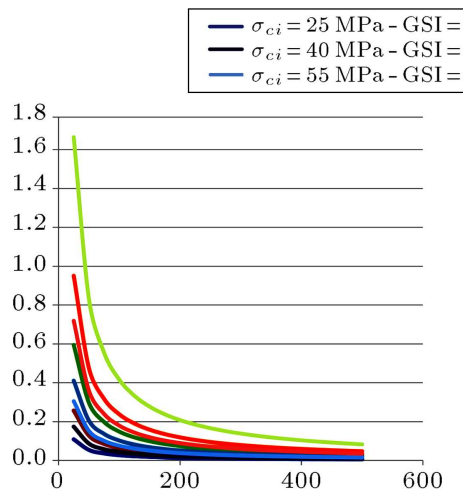

(a)

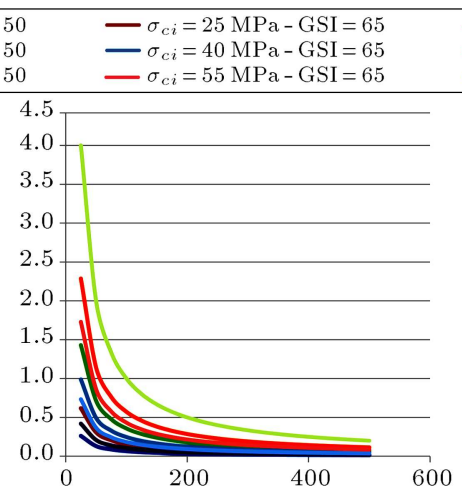

(b)

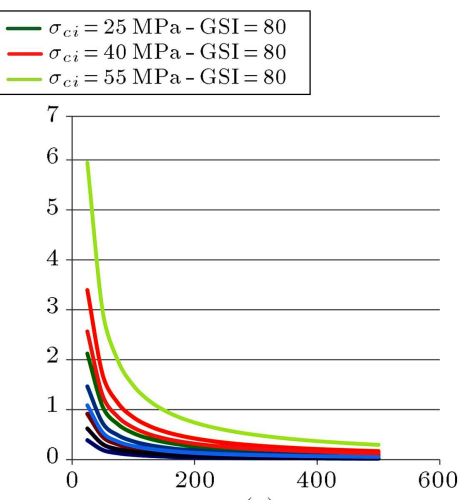

(c)

Figure 8. Minimum local safety factor in the pillar with a variation of the pillar depth $(\mathrm{m})$ for different values of the intact rock uniaxial compressive strength (MPa) and GSI of the rock mass: Case of $l=3 \mathrm{~m}, h=3 \mathrm{~m}:(\mathrm{a}) w_{p} / h_{p}=0.33$, (b) $w_{p} / h_{p}=0.66$, and (c) $w_{p} / h_{p}=1$.

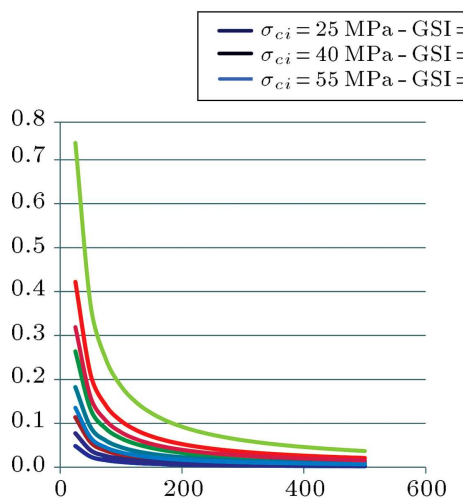

(a)

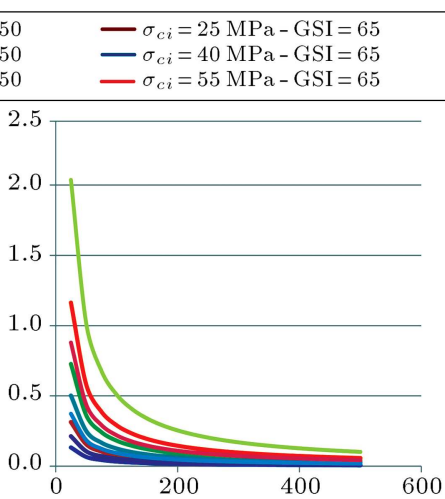

(b)

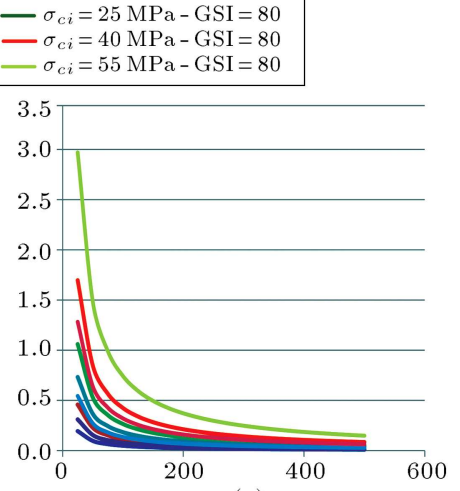

(c)

Figure 9. Minimum local safety factor in the pillar with a variation of the pillar depth $(\mathrm{m})$ for different values of the intact rock uniaxial compressive strength $(\mathrm{MPa})$ and GSI of the rock mass: Case of $l=5 \mathrm{~m}, h=3 \mathrm{~m}:(\mathrm{a}) w_{p} / h_{p}=0.33$, (b) $w_{p} / h_{p}=0.66$, and (c) $w_{p} / h_{p}=1$.

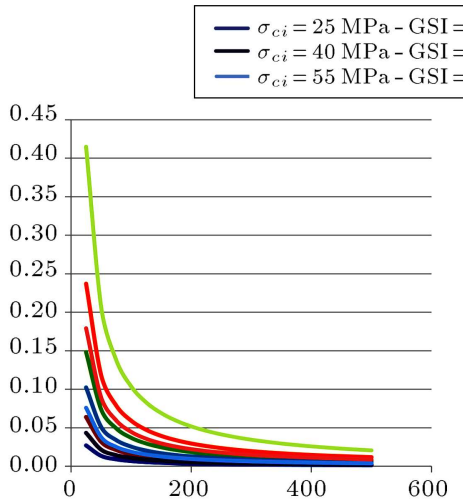

(a)

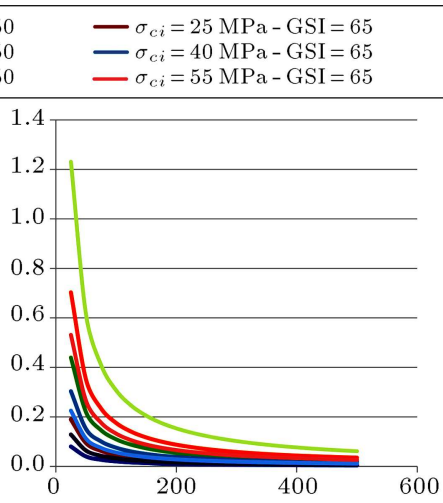

(b)

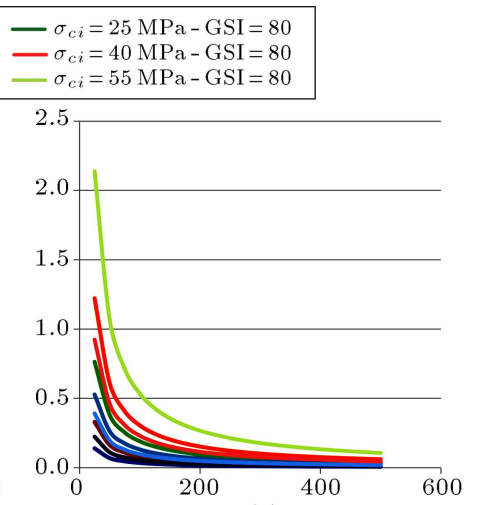

(c)

Figure 10. Minimum local safety factor in the pillar with a variation of the pillar depth $(\mathrm{m})$ for different values of the intact rock uniaxial compressive strength $(\mathrm{MPa})$ and GSI of the rock mass: Case of $l=7 \mathrm{~m}, h=3 \mathrm{~m}:(\mathrm{a}) w_{p} / h_{p}=0.33$, (b) $w_{p} / h_{p}=0.66$, and (c) $w_{p} / h_{p}=1$. 
$h_{p}, l$, and the depth of the pillar $z$ (the disturbance factor $D$ is considered equal to 0 , typical value for undisturbed rock mass). The figures can be used in order to develop a fast pre-dimensioning of a rock pillar, leaving the numerical modelling only to check the defined geometrical configuration.
As an example, a rock pillar at a depth of $75 \mathrm{~m}$, and with a height of $h_{p}=7 \mathrm{~m}$ and a chamber width of $l=7 \mathrm{~m}$ requires a width of $w_{p}=7 \mathrm{~m}\left(w_{p} / h_{p}=1\right)$ in order to have a local minimum safety factor of 2 , if GSI $=80$ and the intact rock strength, $\sigma_{c i}^{\prime}$, is equal to $55 \mathrm{MPa}$.

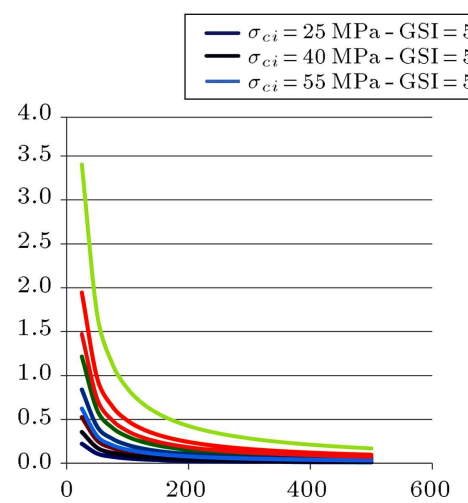

(a)

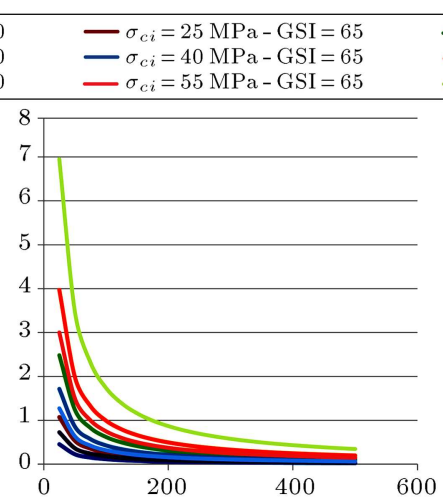

(b)

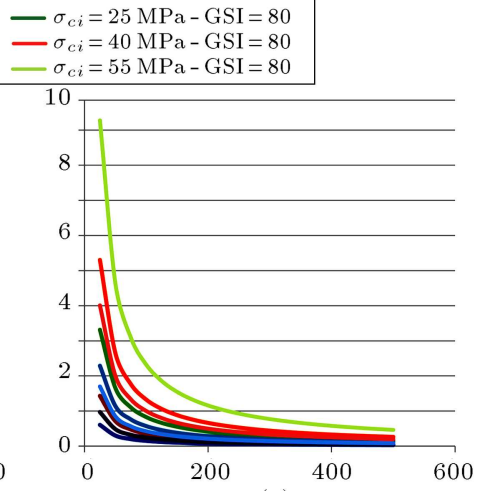

(c)

Figure 11. Minimum local safety factor in the pillar with a variation of the pillar depth $(\mathrm{m})$ for different values of the intact rock uniaxial compressive strength $(\mathrm{MPa})$ and GSI of the rock mass: Case of $l=3 \mathrm{~m}, h=5 \mathrm{~m}:(\mathrm{a}) w_{p} / h_{p}=0.33$, (b) $w_{p} / h_{p}=0.66$, and (c) $w_{p} / h_{p}=1$.

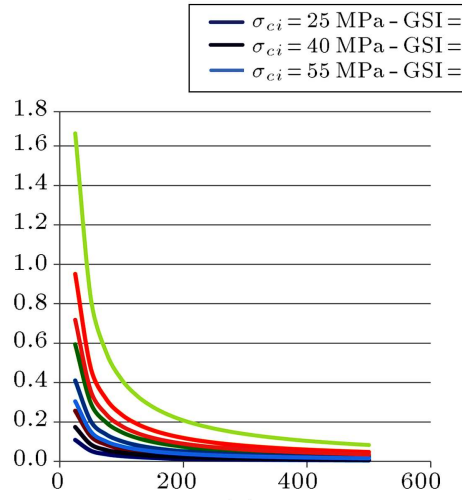

(a)

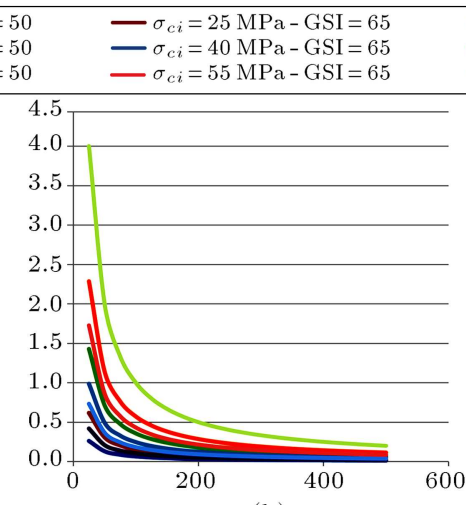

(b)

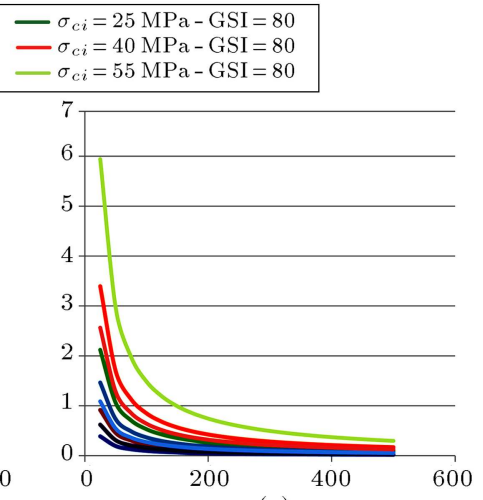

(c)

Figure 12. Minimum local safety factor in the pillar with a variation of the pillar depth $(\mathrm{m})$ for different values of the intact rock uniaxial compressive strength $(\mathrm{MPa})$ and GSI of the rock mass: Case of $l=5 \mathrm{~m}, h=5 \mathrm{~m}:(\mathrm{a}) w_{p} / h_{p}=0.33$, (b) $w_{p} / h_{p}=0.66$, and (c) $w_{p} / h_{p}=1$.

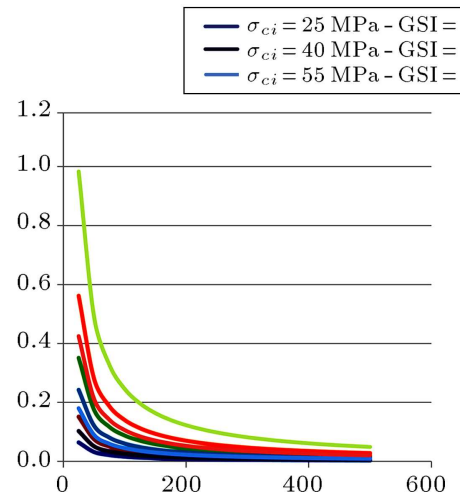

(a)

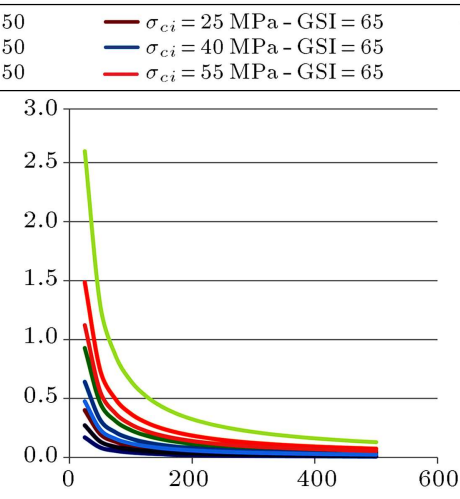

(b)

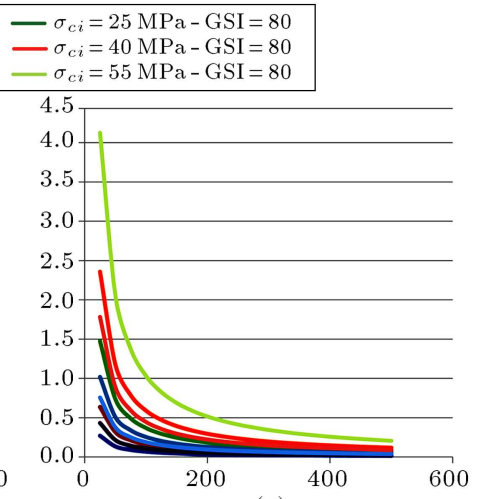

(c)

Figure 13. Minimum local safety factor in the pillar with a variation of the pillar depth $(\mathrm{m})$ for different values of the intact rock uniaxial compressive strength $(\mathrm{MPa})$ and GSI of the rock mass: Case of $l=7 \mathrm{~m}, h=5 \mathrm{~m}:(\mathrm{a}) w_{p} / h_{p}=0.33$, (b) $w_{p} / h_{p}=0.66$, and (c) $w_{p} / h_{p}=1$. 


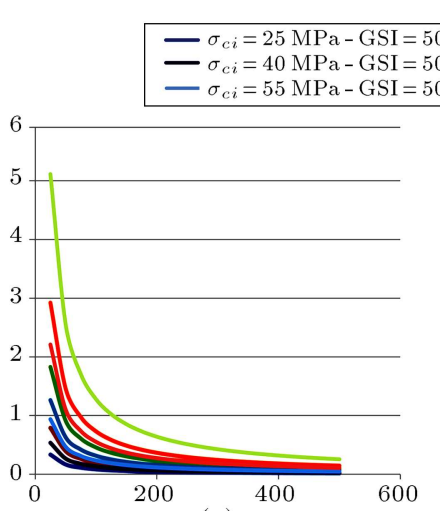

(a)

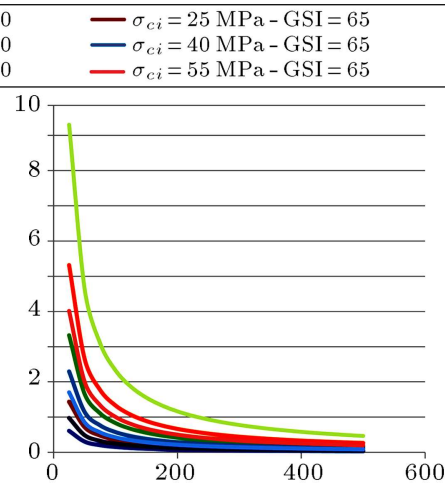

(b)

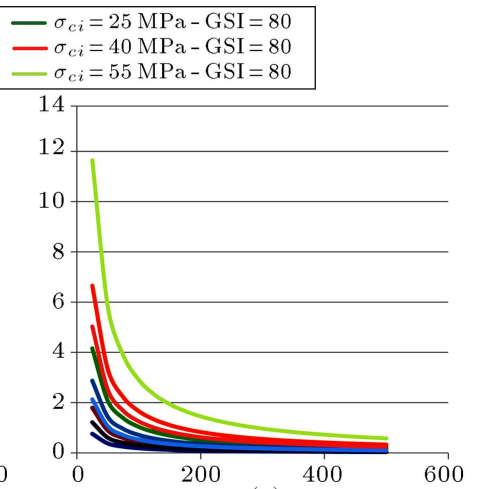

(c)

Figure 14. Minimum local safety factor in the pillar with a variation of the pillar depth $(\mathrm{m})$ for different values of the intact rock uniaxial compressive strength (MPa) and GSI of the rock mass: Case of $l=3 \mathrm{~m}, h=7 \mathrm{~m}:(\mathrm{a}) w_{p} / h_{p}=0.33$, (b) $w_{p} / h_{p}=0.66$, and (c) $w_{p} / h_{p}=1$.

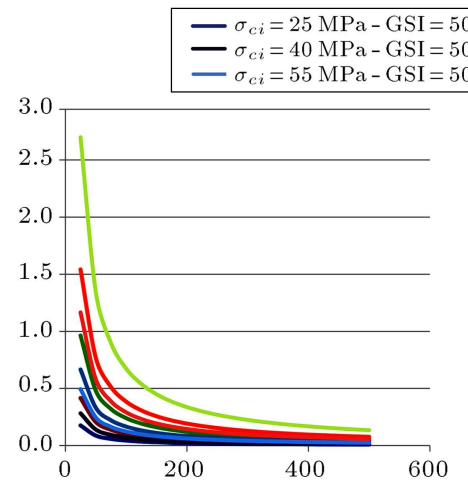

(a)

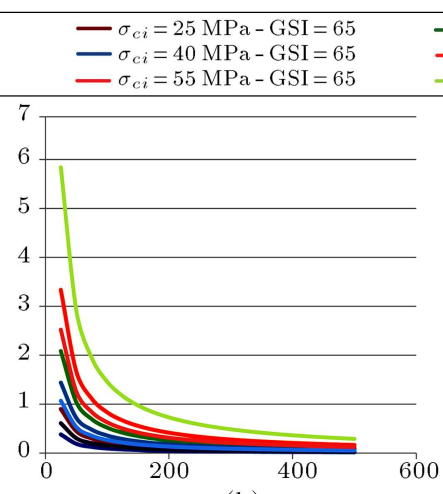

(b)

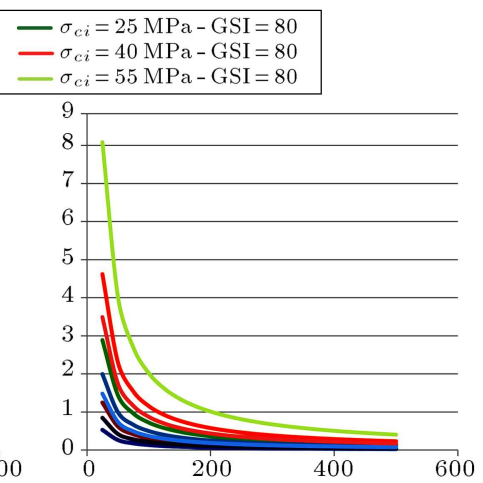

(c)

Figure 15. Minimum local safety factor in the pillar with a variation of the pillar depth $(\mathrm{m})$ for different values of the intact rock uniaxial compressive strength (MPa) and GSI of the rock mass: Case of $l=5 \mathrm{~m}, h=7 \mathrm{~m}:(\mathrm{a}) w_{p} / h_{p}=0.33$, (b) $w_{p} / h_{p}=0.66$, and (c) $w_{p} / h_{p}=1$.

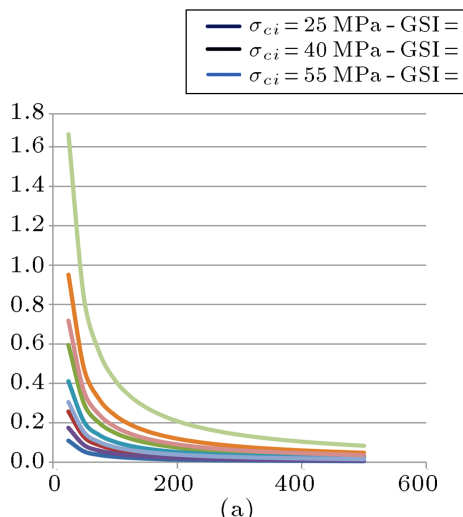

(a)

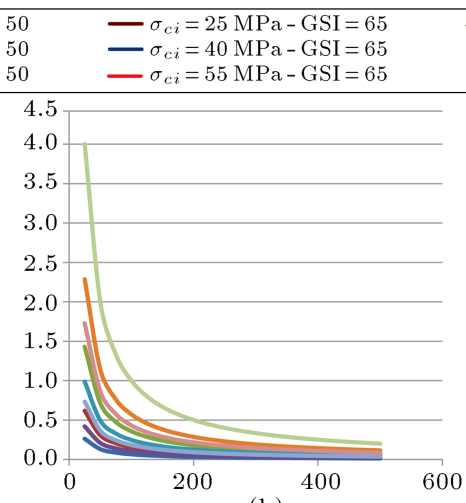

(b)

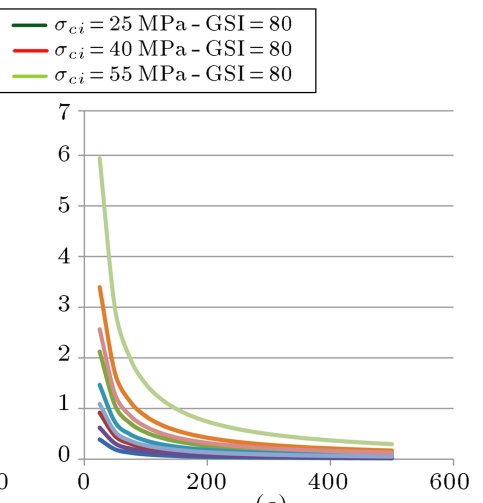

(c)

Figure 16. Minimum local safety factor in the pillar with a variation of the pillar depth $(\mathrm{m})$ for different values of the intact rock uniaxial compressive strength $(\mathrm{MPa})$ and GSI of the rock mass: Case of $l=7 \mathrm{~m}, h=7 \mathrm{~m}:(\mathrm{a}) w_{p} / h_{p}=0.33$, (b) $w_{p} / h_{p}=0.66$, and (c) $w_{p} / h_{p}=1$.

\section{Conclusions}

The area of influence method and some empirical formulations have been adopted in the last decades for the evaluation of the mean axial stress in the pillar and the pillar strength, respectively. The application of these formulations from the literature to practical cases can lead to results that are very different from each other and can also lead to over-dimensioning or critical stability conditions of the pillars.

Moreover, pillars dimensioned with simplified analytical formulations, which have safety factors even 
equal to 4, collapse. This simplified design approach can therefore be considered no longer acceptable.

In this paper, a detailed analysis of the stress state of pillars using three-dimensional numerical modelling was developed. In this way, it was possible to evaluate the stresses inside pillars and, in particular, the major principal stresses and minor principal stresses in a precise manner. An extensive parametric analysis made it possible to analyse 18 different geometric conditions, for typical variations in the width/height and interaxis/width ratios of a pillar. Moreover, 3 different depths of the mining room and 27 types of rock mass, including rock masses with a mean-high strength for which the room and pillar mining method is usually adopted, were hypothesised. Reference was made to the well-known Hoek and Brown strength criterion and the GSI index that described the frequency and conditions of natural discontinuities in order to obtain the local strength of the rock mass. The local safety factor inside the pillars was evaluated for each analysed case as the ratio of the local strength of the rock mass to the existing major principal stress.

From the analyses of all the cases, it was possible to show how the critical point inside the pillars, the one that had the minimum local safety factor, was always located at the same point, at the corners close to the roof of the mining room (at a distance of about $1 / 8$ the height of the pillar from the roof of the room). On the basis of these results, it was possible to determine the major principal stress in the critical point with regards to the width/height ratio of the pillar.

Thanks to the developed parametric study, the local safety factor was calculated at the critical point with regards to the parameters of influence (geometry of the problem, characteristics of the rock mass, and lithostatic stress state at the mining room depth).

The dimensioning of the pillars, on the basis of the local safety factor at the critical point, made it possible to avoid the risk of over-dimensioning or criticality of the pillars from the static point of view and make sure that no point in the pillar could reach rupture. In this way, it was possible to avoid evolutionary phenomenon of global collapse of the pillar, which could sometimes occur suddenly, and phenomenon of localised detachment of rock.

Some figures of the minimum local safety factor were obtained in order to allow a pre-dimensioning of a rock pillar on the basis of the mechanical parameters of the rock mass and the geometrical parameters of the chambers. These figures were derived from the estimation equation of the stress state in the critical point.

\section{References}

1. Esterhuizen, G.S., Dolinar, D.R., and Ellenberger, J.L. "Pillar strength in underground stone mines in the United States", International Journal of Rock Mechanics \& Mining Sciences, 48(1), pp. 42-50 (2011).

2. Peduto, D., Arena, L., Ferlisi S., and Fornaro, G. "Analysis of subsidence phenomena via DInSAR data at different scales", Proceedings of the 8th WSEAS International Conference on Environmental and Geological Science and Engineering EG '15, Salerno, Italy (2015).

3. Mortazavi, A., Hassani, F.P., and Shabani, M. "A numerical investigation of rock pillar failure mechanism in underground openings", Computers and Geotechnics, 36(5), pp. 691-697 (2009).

4. Kaiser, P.K. and Tang, C.A. "Numerical simulation of damage accumulation and seismic energy release during brittle rock failure", Part II: Rib Pillar Collapse. International Journal of Rock Mechanics \& Mining Sciences, 35(2), pp. 123-134 (1998).

5. Jaeger, J.C. and Cook, N.G.W., Fundamentals of Rock Mechanics, 4th Edn., p. 513, Blackwell Publishing, London (2007).

6. Do, N.A., Dias, D., Oreste, P., and Djeran-Maigre I. "2D numerical investigation of segmental tunnel lining behaviour", Tunnelling and Underground Space Technology, 37, pp. 115-127 (2013).

7. Do, N.A., Dias, D., Oreste, P., and Djeran-Maigre, I. "Three-dimensional numerical simulation for mechanized tunnelling in soft ground: The influence of the joint pattern", Acta Geotechnica, 9(4), pp. 673-694 (2014).

8. Do, N.A., Dias, D., Oreste, P., and Djeran-Maigre, I. "Three-dimensional numerical simulation of a mechanized twin tunnels in soft ground", Tunnelling and Underground Space Technology, 42, pp. 40-51 (2014).

9. Ranjbarnia, M., Oreste, P., and Fahimifar, A. "Analytical-numerical solution for stress distribution around tunnel reinforced by radial fully grouted rockbolts", Int. J. Numer. Anal. Meth. Geomech, 40(10), pp. $1844-1862$ (2016).

10. Innaurato, N., Oreste, P., Peila, D., and Castiglia C. "First results of a parametric study through 3D numerical modeling for the study of the behavior of pillars of ornamental stones underground quarries" [Primi risultati di uno studio parametrico attraverso modellazione numerica 3D per lo studio del comportamento dei pilastri di cave sotterranee di pietre ornamentali], in Le cave di pietra ornamentali, Torino, Italy, Ed. Geam, pp. 151-158 (2000).

11. Martin, C.D. and Maybee, W.G. "The strength of hard-rock pillars", International Journal of Rock Mechanics \& Mining Sciences, 37(8), pp. 1239-1246 (2000).

12. Hoek, E. and Brown. E.T., Underground Excavations in Rock, The Institute of Mining and Metallurgy, London (1980).

13. Lunder, P. and Pakalnis, R. "Determination of the strength of hard-rock. mine pillars", Can. Inst. of Min. and Met Bulletin, 90(1013), pp. 51-55 (1997). 
14. Maybee, W.G. "Pillar design in hard brittle rocks", Master's Thesis, School of Engineering, Laurentian University, Sudbury, ON, Canada (1999).

15. Salamon, M.D.G. and Munro, A.H. "A study of the strength of coal pillars", J.S. Afr. Inst. Min. Metall., 65, pp. 55-67 (1967).

16. Hardy, M.P. and Agapito, J.F.T. "Pillar design in oil shale mines", In Proc. 16th US Symp Rock Mech., ASCE, New York, USA, pp. 257-266 (1977).

17. Gonzalez-Nicieza, C., Alvarez-Fernandez, M.I., Menendez-Diaz, A., and Alvarez-Vigil, A.E. "A comparative analysis of pillar design methods and its application to marble mines", Rock Mech. Rock Engng., 39(5), pp. 421-444 (2006).

18. Potvin, Y., Hudyma, M.R., and Miller, H.D.S. "Design guidelines for open slope support", Bull. Can. Min. Metall., 82, pp. 53-62 (1989).

19. Krauland, N. and Soder, P.E. "Determining pillar strength from pillar failure observations", Eng. Min. $J ., 8$, pp. 34-40 (1987).

20. Sheorey, P.R., Loui, J.P., Singh, K.B., and Singh, S.K. "Ground subsidence observations and a modified influence function method for complete subsidence prediction", Int. J. Rock Mech. Min. Sci., 37(5), pp. 801-818 (2000).

21. Itasca, FLAC 3D manual (2006). http://www.itascacg. com/flac3d/index.php

22. Guarascio, M. and Oreste, P. "Evaluation of the stability of underground rock pillars through a probabilistic approach", American Journal of Applied Sciences, 9(8), pp. 1273-1282 (2012).

23. Oreste, P. "Stability of rock pillars with singular and persistent discontinuities", American Journal of Applied Sciences, 9(9), pp. 1354-1372 (2012).

24. Lederer, M. and Khatibi, G. "Finite element implementation of a novel version of strain gradient elasticity", Proceedings of the 6th WSEAS International Conference on Theoretical and Applied Mechanics TAM '15, Salerno, Italy (2015).

25. Hoek, E. and Brown, E.T. "Practical estimates or rock mass strength", Int. J. Rock Mech. Min.g Sci. \& Geomech. Abstr., 34(8), pp. 1165-1186 (1997).

26. Hoek, E., Carranza-Torres, C. and Corkum, B. "HoekBrown failure criterion-2002 edition", In: Proceedings of the 5th North American Rock Mechanics Symp., Toronto, Canada, 1, pp. 267-73 (2002).

27. Hoek, E. "A brief history of the development of the Hoek-Brown failure criterion", Soils and Rocks, 30(2), pp. 85-92 (2007).
28. Cai, M., Kaiser, P.K., Uno, H., Tasaka, Y., and Minami, M. "Estimation of rock mass deformation modulus and strength of jointed hard rock masses using the GSI system", International Journal of Rock Mechanics \& Mining Sciences, 41(1), pp. 3-19 (2004).

29. Marinos, P. and Hoek, E. "GSI: a geologically friendly tool for rock mass strength estimation", Proc. International Conference on Geotechnical \& Geological Engineering, GeoEng 2000, Technomic Publ., Melbourne. Australia, pp. 1422-1442 (2000).

30. Wei, R., Zhang, S., Karunasena, W., Sivakugan, N., and Zhang, H. "Blast simulation in underground mines using the combined finite-discrete element method", Proceedings of the "th WSEAS International Conference on Simulation, Modelling and Optimization, Beijing, China (2007).

31. Singh, M. and Rao, KS. "Empirical methods to estimate the strength of jointed rock masses", Engineering Geology, 77(1-2), pp. 127-137 (2005).

32. Laubscher, D.H. "Design aspects and effectiveness of support systems in different mining conditions", Trans Instn. Min. Metall., 93, pp. A70-A82 (1984).

\section{Biographies}

Masoud Ranjbarnia is Assistant Professor of Geotechnical Engineering at University of Tabriz. He finished his $\mathrm{PhD}$ program at Amirkabir University of Technology, Tehran, Iran (Tehran Polytechnic) in 2014. He also conducted a part of his $\mathrm{PhD}$ thesis at Politechnico di Torino University, Italy. After graduation, he has continued his research in the field of underground structures and prepared some papers.

Pierpaolo Oreste is Full Professor of Geotechnical Engineering at Politecnico di Torino University, Italy. He has conducted fascinating research over the last twenty years, particularly in the area of tunneling and underground structures. He has numerous publications, 77 being peer-reviewed international journal publications with 660 citations.

Ahmad Fahimifar is Full Professor of Geotechnical Engineering at Amirkabir University of Technology, Tehran, Iran. He is specialist in rock mechanics and tunnel engineering. Over the last twenty five years, he has been the supervisor of numerous master and $\mathrm{PhD}$ students. In the recent ten years, he has authored or co-authored more than 120 published papers in international journals. 